\title{
Landmark based shape variation of normal male, female and sex-reversed tilapia (Oreochromis niloticus) in Bangladesh
}

\author{
R Moushomi, S Saha \\ Department of Fisheries and Marine Science, Noakhali Science and Technology University, Sonapur, \\ Noakhali 3814
}

\begin{abstract}
The truss network systems constructed with the help of landmark were evaluated to infer the shape of normal male, female and monosex male tilapia. A total of sixty (60) individuals from different sources (Subarna Agro Based Initiative and BismillahAgro Production) were collected during September-December, 2013. All the data of the studied characteristics were obtained using the digital photograph of the samples which were analyzed through professional image measurement software. Nine morphometric and eight meristic characters were considered along with twenty six truss network measurements. Highly significant difference $(\mathrm{P}<0.05)$ was observed in six (SL, HL, PrDL, MBH, EL and PL) of eight morphometric measurements. In case of truss measurements 7 of 26 measurements showed highly significant differences among the groups. For both morphometric and landmark measurements the first DF accounted for $98.9 \%$ and $85.7 \%$ and the second DF accounted for $1.1 \%$ and $14.3 \%$ respectively. With truss network system $100 \%$ monosex male samples, $85.5 \%$ of normal male samples, $100 \%$ of female samples were correctly classified. In both cases, plotting discriminant functions revealed high isolation of the groups especially between the monosex groups with the other two groups. The results showed that the shape of the tested tilapia groups significantly differed from each other depending on the truss measurements. that could be explained by the genetic sex related reasons.
\end{abstract}

Key words: Landmark, oreochromis niloticus, monosex, morphometric, meristic

Progressive Agriculturists. All rights reserve

*Corresponding Author: mou.d.rashnat@gmail.com

\section{Introduction}

Tilapia is a genus of cichlid fishes endemic to freshwater habitats in Southern Africa. In the past this was a very large genus including all species with the common name tilapia, but today the vast majority is placed in other genera. In the past, Oreochromis and Sarotherodon were retained in the genus Tilapia, but these are treated as separate genera by all recent authorities. Nile tilapias are hardy individuals that are easy to harvest, making them a good aquacultural species. They have a mild, white flesh that is appealing to consumers. This species constitutes about $4 \%$ of the total tilapia aquaculture production worldwide. Tilapia can become problematic invasive species in new warm-water habitats, whether deliberately or accidentally introduced, but generally not in temperate climates due to their inability to survive in cooler waters below about $21^{\circ} \mathrm{C}\left(70^{\circ} \mathrm{F}\right)$ (Wikipedia, 2014).

Morphometric and meristic characters of fish are the measurable or countable characters common in all fishes. Landmarks are some selected arbitrary points in fish body and with the help of these points the individual fish shape can be analyzed. A landmark is a point of correspondence on each object that matches between and within groups. Shape is all the geometrical information that remains when location, scale and rotational effects are filtered out from an object. The truss network systems constructed with 
the help of landmark points are powerful tools for stock identification.

The objectives of the study was to evaluate the variation in morphometric and meristic characters of Nile tilapia among three groups (monosex male, normal male and normal female) collected from the hatchery and to assess and describe the shape variation of among the group of collected fishes.

\section{Materials and Methods}

Sixty Nile tilapia of different size was collected in live condition from two stocks (Table 1).

Table 1. Details of the samples collected from different groups

\begin{tabular}{|l|l|l|l|l|}
\hline Stock & Status of fish stocks & Month of collection & Number & Range (cm) \\
\hline $\begin{array}{l}\text { Subarna Agro Based } \\
\text { Initiative }\end{array}$ & Reared & September, 2013 & 20 (Monosex) & $13.5-20.35$ \\
\hline $\begin{array}{l}\text { Bismillah Agro Production, } \\
\text { BAP }\end{array}$ & Hatchery seed & December, 2013 & 20(Male) & $11.46-21.86$ \\
\hline $\begin{array}{l}\text { Bismillah Agro Production, } \\
\text { BAP }\end{array}$ & Hatchery seed & December, 2013 & 20(female) & $10.7-17.72$ \\
\hline
\end{tabular}

Ten morphometric characters (Total length (TL), Standard length (SL), Fork length (FL), Head length (HL), Maximum body height (MBH), Eye length (EL), Pre orbital length (PrOL), Post orbital length (POL), Peduncle length (PL), Pre dorsal length (PrDL) of the fish were measured respectively. A total of eight meristic characters (Dorsal fin rays, Pectoral fin rays, Pelvic fin rays, Anal fin rays, Caudal fin rays, Lateral line scale, Scale above lateral line, Scale below lateral line) were analyzed in the study. Twelve landmarks determining twenty six distances were measured on the body (Figure 1).

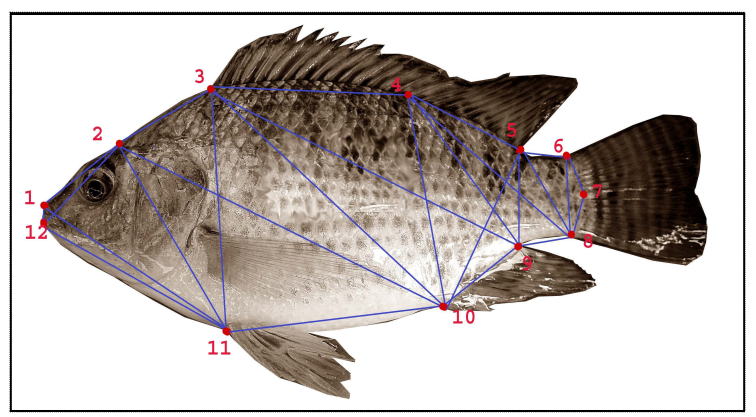

Figure 1. Locations of 12 landmarks used for shape analysis of Oreochromis niloticus

For the need of the proper way of analysis, it was necessary to eliminate any size effect from the data set. It was necessary to remove size-dependent variation for all the characters. An allometric formula given by Elliott et al. (1995) was used to remove the size effect from the collected data set: $\mathrm{M}_{\mathrm{adj}}=\mathrm{M}\left(\mathrm{L}_{\mathrm{s}} /\right.$ $L_{o}$ ) ${ }^{b}$, Where, $M$ : original measurement, $M_{\text {adj }}$ : size adjusted measurement, $L_{o}$ is the total length of fish and $L_{s}$ is overall mean of total length for all fish from all samples.

Parameter b was estimated for each character from the observed data as the slope of the regression of log $M$ on $\log L_{0}$, using all fish in all groups. The efficiency of size adjustment transformations was assessed by testing the significance of the correlation between transformed variable and total length.

Univariate analysis of variance (ANOVA) was carried out to test the significance of morphological differences. In addition, size adjusted data were standardized and submitted to discriminant function analysis (DFA) using SPSS v 16.0. Comparison of meristic characters was done using non-parametric statistical test (Kruskal-Wallis test) also by SPSS v 16.0.

\section{Results}

Meristic counts: Meristic counts of all samples ranged from 27-30 (median, $\mathrm{m}_{\mathrm{e}}=28$ ) for dorsal fin rays, 14-19 $\left(\mathrm{m}_{\mathrm{e}}=16\right)$ for caudal fin rays, 10-13 $\left(\mathrm{m}_{\mathrm{e}}=\right.$ 12) for anal fin rays, for pelvic fin rays $5-6\left(m_{e}=6\right)$, 10-12 $\left(\mathrm{m}_{\mathrm{e}}=11\right)$ for pectoral fin rays, 24-19 $\left(\mathrm{m}_{\mathrm{e}}=26\right)$ for lateral line scale, 15-28 $\left(\mathrm{m}_{\mathrm{e}}=26\right)$ for scale above lateral line, 23-30 $\left(\mathrm{m}_{\mathrm{e}}=27\right)$ for scale below lateral 
line. In this experiment, meristic counts were compared among three groups (monosex male, normal male and normal female). The mean number of anal, pelvic fin rays and scale below lateral line were not different among fish from these groups (Kruskal-Wallis test, $\mathrm{P}>0.05$ ) and difference were occurred in other characters (Caudal fin rays, $\mathrm{P}<0.05$; scale above lateral line, $\mathrm{P}<0.05$ and pectoral fin rays, $\mathrm{P}<0.05)$.

\section{Morphomeristic and landmark measurements:} Efficiency of the allometric formula in removing size effect from the data was justified by using correlation between total length and the adjusted character. Total length were excluded first and not transformed because using this parameter as standard all other parameters were standardized.

Among the nine transformed morphometric measurements, the six (Standard length (SL), Head length (HL), Pre dorsal length (PrDL), Maximum body height (MBH), Eye length (EL), and Peduncle length, PL) of eight measurements were found significantly different $(\mathrm{P}<0.05)$ among the groups. Univariate statistics (ANOVA) showed that seven (Point 1 to 2, Point 12 to 2, Point 2 to 11, Point 3 to11, Point 3 to 10, Point 4 to 10, Point 5 to 9 ) of twenty six measurements were significantly different among samples in varying degrees (Table 2).

Discriminant function analysis produced two discriminant functions (DF1 and DF2) for both morphometric and landmark measurements. For morphometric and landmark measurements the first DF accounted for $98.9 \%$ and $85.7 \%$ and the second DF accounted for $1.1 \%$ and $14.3 \%$, respectively of among group variability, explaining $100 \%$ of total among groups variability.

Monosex group were clearly separated from the other other two groups (Normal male and Normal Female) of the discriminant space with virtually no overlapping. This suggested that there was no intermingling among Monosex male groups and other two groups. But the normal male and normal female groups are found to mingle in some extents.

With truss network system all the samples were more clearly separated from each other in the discriminant space in Fig. 2. Pooled within-groups correlations between discriminant variables and DFs revealed that among the nine morphometric measurements- Head length (HL) and Peduncle length (PL) dominantly contributed to first DF and the rest six (Eye length EL, Pre orbital length-PrOL, Post orbital lengthPOL, Standard length-SL, Pre dorsal length-PrDL, Maximum body height-MBH) contributed to the second DF in Table 3.

Table 2. Univariate statistics (ANOVA) testing differences among samples from all truss measurements

\begin{tabular}{|c|c|c|c|}
\hline & Wilks' Lambda & $\mathbf{F}$ & Significance \\
\hline adj 1-2 & .794 & 7.250 & $.002 * *$ \\
\hline Adj 2-3 & .987 & .361 & .699 \\
\hline adj 3-4 & .934 & 1.979 & .148 \\
\hline adj 4-5 & .925 & 2.271 & .113 \\
\hline adj 5-6 & .952 & 1.422 & .250 \\
\hline adj 6-7 & .934 & 1.980 & .148 \\
\hline adj 7-8 & .950 & 1.470 & .239 \\
\hline adj 8-9 & .998 & .065 & .937 \\
\hline adj 9-10 & .998 & .048 & .953 \\
\hline adj 10-11 & .979 & .587 & .559 \\
\hline adj 11-12 & .944 & 1.667 & .198 \\
\hline adj 12-1 & .961 & 1.146 & .325 \\
\hline adj 12-2 & .764 & 8.640 & $.001^{* *}$ \\
\hline adj $1-11$ & .911 & 2.737 & .073 \\
\hline adj 2-11 & .858 & 4.636 & $.014^{*}$ \\
\hline adj 2-10 & .908 & 2.833 & .067 \\
\hline adj 3-11 & .756 & 9.059 & $.000 * * *$ \\
\hline adj 3-10 & .787 & 7.585 & $.001^{* *}$ \\
\hline adj 3-9 & .988 & .329 & .721 \\
\hline adj 4-10 & .866 & 4.337 & $.018^{*}$ \\
\hline adj 4-9 & .925 & 2.269 & .113 \\
\hline adj 4-8 & .974 & .750 & .477 \\
\hline adj 5-10 & .987 & .377 & .688 \\
\hline adj 5-9 & .810 & 6.552 & $.003^{* *}$ \\
\hline adj5-8 & .965 & 1.009 & .371 \\
\hline adj 6-8 & .982 & .525 & .594 \\
\hline
\end{tabular}

$* \mathrm{P}<0.05$, ** $\mathrm{P}<0.01, * * * \mathrm{P}<0.001$

In case of truss measurements, among the twenty two measurements 14 measurements- 3 to 11,12 to 2,3 to 10,1 to 2,5 to 9,2 to 11,4 to 10,4 to 11,2 to 10 , 1 to 11,4 to 9,11 to 12,2 to 3,3 to 9,9 to 10 
dominantly contributed to first DF and the rest 12 contributed to the second DF.

Table 3. Pooled within-groups correlations between discriminating variables and discriminant functions (variables ordered by size of correlation within function, *denotes the largest correlation between each variable and discriminant functions)

\begin{tabular}{|l|c|c|}
\hline \multirow{2}{*}{ Characters } & \multicolumn{2}{|c|}{ Function } \\
\cline { 2 - 3 } & DF1 & DF2 \\
\hline Head length (HL) & $.735^{*}$ & .067 \\
Peduncle length (PL) & $.155^{*}$ & -.099 \\
Eye length (EL) & -.017 & $-.721^{*}$ \\
Pre orbital length (PrOL) & .002 & $.334^{*}$ \\
Post orbital length (POL) & .025 & $.281^{*}$ \\
Standard length (SL) & .128 & $.273^{*}$ \\
Pre dorsal length (PrDL) & .059 & $-.169^{*}$ \\
Maximum body height & .071 & $-.153^{*}$ \\
(MBH) & & \\
\hline
\end{tabular}

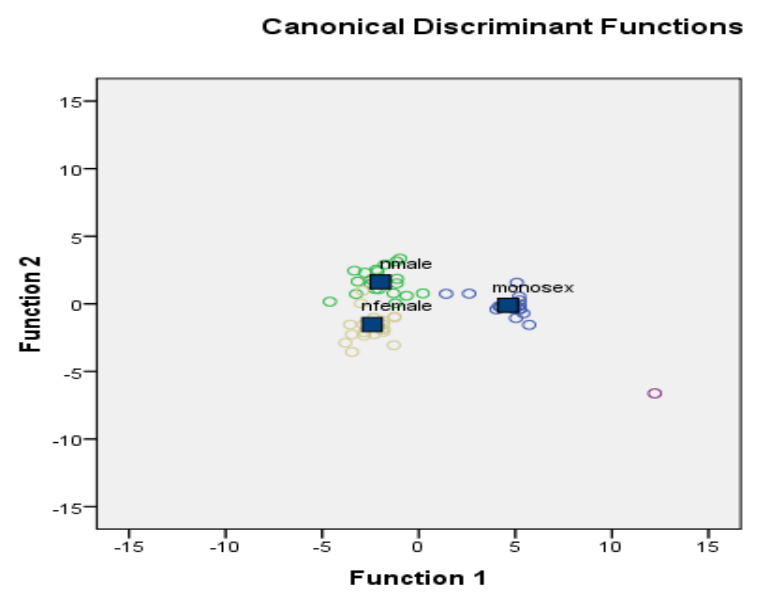

Figure 2. Sample centroids of discriminant function scores based on truss measurement. Samples referred to 1.Monosex male Group, 2. Normal Male group and 3. Normal Female group.

\section{Discussion}

In the present study, meristic counts of all samples ranged from 27-30 rays for dorsal fin, 10-12 rays for pectoral fin, 5-6 rays for pelvic fin, 10-13 rays for anal fin and 14-19 rays for caudal fin, 24-19 Lateral line scale, 15-28 scale above lateral line and 23-30 scale below lateral line. Since meristic characters were independent of size of the fish and did not change during growth (Murta, 2008) the raw meristic data were used in analysis. The mean number of the six (SL, HL, PrDL, MBH, EL and PL) of eight measurements were found significantly different $(\mathrm{P}<0.05)$ with varying degrees.

From the present study of these three groups, it is found that there are much differences among them from the view point of morphomeristic analysis through Canonical Discriminant functions view that is based on the supplied data. (Vidalis et al.,1994) argued that meristic characters may follow a predetermined variability at a very narrow range, because divergence of the meristic counts from a standard range could be fatal for the individual. Several authors have considered meristic characters less useful than the morphometric data (Misra and Carscadden et al., 1987) when comparing morphological variations.

Morphomeristic characters can show high plasticity in response to differences in environmental conditions like food abundance and temperature (Allendorf and Phelps et al., 1988; Swain et al., 1999; Wimberger, 1992). In general, fishes demonstrate greater variance in morphological traits both within and between groups than other vertebrates, and are more susceptible to environmentally-induced morphological variation (Allendorf et al., 1980; Wimberger et al., 1992). Fishes adapt quickly by modifications of their physiology and behaviour to the environmental change. These modifications finally change their morphology. The monosex male group that were taken in account for the study is found to show greater variation than the rest of two groups because of their feeding habit conducted with hormonally treated feed to stop their breeding incidence so that they can grow fast to meet the demand of extra protein for the growing group and also for their genetic sex related reasons. 
From landmark based point of view: Truss network measurements were also conducted in the present experiment. It is a powerful tool for identifying phenotypic stocks of fish species (Turan and Erguden et al., 2004; Turan et al., 2004). An unbiased network of morphometric measurements over the two dimensional outline of a fish removes the need to find the types of characters and optimal number of characters for stock separation, and provides information over the entire fish form (Turan et al., 2004).

The truss network system can be effectively used to distinguish between the monosex groups, normal male groups and normal female groups. From the conducted analysis it is expected to get more significant differences because of different groups with different feeding conditions. From the analysis through Canonical Discriminant functions depending on the truss measurements it is found that there was no overlapping among the groups that indicates that the three fish group samples are different from the point of landmark counts also. The findings of the present study would significantly contribute towards designing of such a detailed study in future.

\section{Reference}

Allendrof FW, Ryman N, Utter F (1987). Genteics and fishery management: Past, present and future in population genetics and fishery management. University of Washington Press, Seattle \& London, 1-20.

Allendrof FW, Phelps SR (1980). Loss of genetic variation in hatchery stock of Cutthroat trout. Transections of the American. Fisheries Society, 109: 537-543.

Elliot NG, Haskard K, Koslow JA (1995). Morphomeritrick analysis of orange roughy
(Hoplostethus atlanticus) of the continental slope of southern Australia. Journal of Fish Biology, 46: 202-220.

Misra RK, Carscadden JE (1987). A multivariate analysis of morphometrics to detect differences in populations of capelin (Mallotus villosus). Journal of Marine Science. 43: 99-106.

Murta AG, Pinyo AL, Abaunza P (2008). Stock identification of horse mackerel (Trachurus trachurus) through the analysis of body shape. Fish Research, 89: 152-158.

Swain DP and Foote CJ (1999). Stocks and chameleons the use of phenotypic variation in stock identification. Fish Research, 43: 113128.

uran C (2004). Stock identification of Mediterranean horse mackerel (Trachurus mediterraneus) using morphometrics and meristic charecters. Journal of Marine Science and Technology, 61: 774-781.

uran C, Erguden D, Turan S, Gurlek M (2004). Genetic and morphologic structure of Liza abu (Heckel, 1843) populations from the Rivers Orontes, Euphrates and Tigris. Turkish Journal of Veterinary and Animal Science, 28: 729734.

idalis K, Markakis G, Tsimenides N (1994). Discrimination between populations of picarel (Spicara smaris L., 1758) in the Aegean Sea, using multivariate analysis of phonetic characters. Fish Research, 30: 191-197.

imberger PH (1992). Plasticity of fish body shape, the effects of diet, development, family and age in two species of Geophagus (Pisces: Cichlidae). Biological Journal of the Linnean Society. 45: 197-218. 